\title{
Editorial
}

\section{Possessividade e Fobia: uma reflexão para agora}

\section{Possessiveness and Phobia: a reflection for now}

Gisálio Cerqueira Filho*1

Escrevemos este Editorial nos primeiros dias do novo ano de 2021, saudando o mítíco Deus Jano, olhos postos na esperança de que Yemanjá nos possa acolher no dia 2 de fevereiro. Pedimos a complacência dos leitores. Há estilo, mas não é decorativo, nem regular, nem fluente. Hospedamo-nos na obra de Silviano Santiago (2020): "É estilo pelo lado de dentro do corpo, presente na composição, e está, portanto, em relação homológica à sucessão intermitente de grafiasde-vida expressas por crises. Vou aos solavancos, volto ao revés (se estou em mau caminho), sigo de revés (de modo oblíquo) em acessos sucessivos" (pp. 94-95). Assim abordaremos temas vários que compõem o mosaico atual. Os conceitos de "individualismo possessivo" (Mcpherson, 1979) e "individualismo fóbico" (Cerqueira Filho, 2002) orientam o que temos trabalhado nas últimas décadas. Se o primeiro construto converte o indivíduo em um obsessivo pela propriedade, num

${ }^{* 1}$ Universidade Federal Fluminense - UFF (Niterói, RJ, Brasil). 
cenário de luta permanente, o segundo rejeita o Outro como inimigo e sob o signo da fobia. Nos anos setenta do século XX, não havia caminho melhor para defender o liberalismo do que problematizar o próprio liberalismo na hora de seu nascimento, ou seja, no momento mesmo que se opõem, no pensamento político inglês do século XVII, Thomas Hobbes e John Locke. Ambos teriam compartilhado algo em comum: a noção de indivíduo e o sentimento de possessividade. Inscritos em certa idealização, seja do mercado perfeito (economia) seja do modelo de príncipe (política), apresentaram-se como arautos do que viria: a burguesia, fosse mais autoritária (absolutista) ou mais liberal. O futuro, já no início do século XX, esclareceu o imbróglio. Nos extremos projetaram-se: a teoria do laissez-faire, laissez passer e o totalitarismo nazi-fascita. Para Macpherson, o "possessivo" era adjetivo idealizado para o indivíduo, também perfeito, proprietário de si, com as suas qualidades e particularidades individuais desde o nascimento e que seriam exclusivos de cada ser humano. Havia nessa história um cheiro de claustro e incenso no ar; o pensamento de Santo Agostinho que, timidamente, dava as mãos a Santo Tomás de Aquino (século XIII, primeira escolástica), mas negando de princípio, a sociedade, como tal. No limite as sociedades seriam individualistas ou holistas (Dumont, 1966; 1976; 1986), apresentando-se a democracia como possibilidade exclusiva nas sociedades individualistas... Nossa perspectiva não está calcada nessa metafísica nem no conceito de Natureza Humana, pois pensávamos a dupla Hobbes/Locke em outro diapasão (Garmendia \& Schnaith, 1973). Para nós, ambos eram filhos da revolução burguesa propiciada pelo capitalismo que se anunciava. Assim, liberalismo/ autoritarismo eram "cara e coroa" de uma mesma moeda; filhos de uma mesma mãe, a revolução burguesa... Isto não significa tratar o totalitarismo absolutista burguês e o liberalismo como a mesma coisa. Enquanto ideologias, são distintas, porém decididamente comprometidas com o Capital e o mercado.

Isto posto, com projeto de pesquisa sob o título "Vulnerabilidade Psíquica, Poder e Teoria Política", temos nos dedicado à relação entre "subjetividade e política", com vários produtos publicados e em circulação. Visávamos dar um duplo passo, de continuidade e ruptura, com relação aos estudos que vimos realizando acerca das relações entre Teoria Política, Psicanálise, Subjetividade, História e mudança política (Neder, 2007). Se há mais de cem anos a Psicologia, inclusive a Psicologia Clínica, já reivindicava o seu poder heurístico entre as Humanidades e frente à Sociologia, imaginemos hoje em dia. A hora é propícia para recordar o exemplo de Sigmund Freud ao convidar o jurista, e ainda tão jovem Hans Kelsen, para escrever na sua 


\section{EDITORIAL}

Revista de Psicanálise (Kelsen, 1922). ${ }^{1}$ Isto significa dizer da importância da transdisciplinaridade no momento que vivemos. Freud, com uma Revista Internacional de Psicanálise, e que desponta no horizonte científico, em 1922, abre as páginas da revista para temas como "O conceito de estado e a psicologia social com especial consideração da teoria de massa de Freud". Mas não só, pois logo abaixo da expressão IMAGO está escrito "Zeitschrift für Anwendung der Psychoanalyse auf die Geisteswissenschaften" cuja tradução para o português — periódico da aplicação da psicanálise às humanidades - confere todo o sentido a uma revista de psicanálise ao buscar laços com as humanidades (sociologia, direito, linguística, teoria política, história, antropologia, filosofia etc.). E se tal paradigma se achega ao domínio da arte (literatura, escultura, pintura, música e muitas outras) merece a denominação de paradigma estético-expressivo. Laços aqui referidos tanto à aplicação teórica quanto prática, isto é, clínica, e para não falar, ainda, do método. Cumpre ressaltar que mais abaixo do nome IMAGO está anotado HERAUSGEGEBEN VON Dr. SIGM. FREUD - REDIGIERT VON Dr. OTTO RANK u. Dr. HANNS SACHS (Publicado pelo dr. Sigmund Freud e Editado pelo dr. Otto Rank e dr. Hanns Sachs). Presentemente estamos Gizlene Neder (UFF), eu próprio, mais o doutor Ricardo Bomann (Bremen, Alemanha) trabalhando no desenvolvimento da importância do editor Hans Sachs naquele contexto (Cerqueira Filho \& Neder, 2020). Sigmund Freud sempre teve preocupação em não permitir sua submissão à medicina e à psiquiatria. Sachs esteve no grupo íntimo de Freud e desfrutou da sua amizade. Uma ocasião Freud disse: "Apesar do pouco tempo que nos conhecemos, minha confiança nele é ilimitada". ${ }^{2}$ Quando falamos de transdisciplinaridade estamos querendo dizer da "costura" heurística de conceitos múltiplos e bem selecionados; conceitos que produzem certo emaranhamento teórico, o que não é trivial (Barreto Coutinho \& Lima Fonteles, 2019). Aqui a pluridisciplinaridade cede na busca de um enfoque transdisciplinar preciso e que se apoia na democracia do conhecimento (Innerarity, 2011) e no compartilhamento coletivo desse mesmo conhecimento. Um tal paradigma implica o acolhimento do imprevisto na abordagem de um fenômeno a ser explicado ou interpretado. Em inglês, por

${ }^{1} \mathrm{O}$ conceito de estado e a psicologia social com especial consideração da teoria de massa de Freud (1914/1987), pp. 97-197.

2 "Malgrado il poco tempo da cui ci conosciamo", ne disse Freud, "la mia fiducia in lui è sconfinata" Para detalhes da relação ver Sachs (2017). 
exemplo a expressão the grip of ideology (a pegada da ideologia) diz bem da importância da tríade lacaniana RSI (Real, Simbólico, Imaginário) que alarga aquilo que assinala e marca o humano. Daí, muitas vezes, o quanto a presença da arte é importante, mormente a música, pois de improviso se trata, conforme gosta de frisar os veteranos músicos/maestros Hermeto Pascoal e Itiberê Swarg. Tal tese tem sido crescentemente acolhida.

Sim, pensamos que podemos falar de continuidade, porque nos mantemos no campo de saber da teoria política e sociológica, mas também de ruptura, porque nos aproximamos decididamente de questões práticas (novas subjetividades) relacionadas ao mal-estar psíquico vivido na contemporaneidade pós-moderna e que nos fragiliza politicamente, sobretudo diante da autoridade autoinvestida de poder autoritário. Aqui, muitos se interrogam sobre as autoridades afetuosas de suas respectivas vidas que, todavia, exerceram o tal autoritarismo afetivo (Cerqueira Filho, 2005). O que tem presença/função, de autoridade para cada um? Como tal autoridade articula afeto e autoritarismo na vida de cada qual? Como se realiza, na prática, o amor do censor para utilizar a expressão de Pierre Legendre? (Legendre, 1983).

Fizemos uma reflexão experimental com a expressão "vulnerabilidade", 14 ela que foi de certo modo apropriada pela Criminologia Crítica, com Eugenio Raul Zaffaroni (1991; 2004), magistrado; e logo pelo criminólogo holandês Louk Houlsman (1993), os dois discutindo "vulnerabilidade criminológica". Podemos certamente realçar a verdadeira situação de vulnerabilidade diante do Direito Penal, por exemplo, de largos contingentes pobres e de origem afrodescendente, e pelo mundo afora, sejam na América Latina, nos EUA, na Europa, no Oriente etc. que são marcados por uma tal vulnerabilidade. $\mathrm{O}$ grito que ecoa em inglês Black Lives Matter (Vidas negras importam) diz bem do que estamos abordando. Outros juristas, criminólogos, cientistas sociais, enveredaram pelo que acabou recebendo a denominação de "criminologia crítica" como Lola Aniyar de Castro (Maracaibo, Venezuela), Alessandro Baratta (Saarbucken, Alemanha), Emílio Garcia Mendez (UBA-Argentina), tendo atuado no UNICEF do Brasil por ocasião da luta pelo ECA-Estatuto da Criança e do Adolescente), Tereza Miralles (Barcelona, Espanha), Nilo Batista (UERJ-Brasil), Vera Malaguti (UERJ-Brasil), Gizlene Neder (UFF-Brasil). Um bom número destes se reuniram, liderados pelo jurista Nilo Batista, no Programa de Mestrado em Criminologia da UCAM (Universidade Cândido Mendes), na virada do século XX/XXI.

Entretanto, ao nomear um periódico como de "Psicopatologia Fundamental" estamos sublinhando o sofrimento humano e especialmente psíquico 


\section{EDITORIAL}

que acompanha a constituição mesma desse humano, como ressaltam Freud (1914/1987), Pierre Fédida (1991) e Manoel Berlinck (2000). Este último observa:

[...] queremos estudar uma tal vulnerabilidade, que nomeamos "insuficiência imunológica psíquica" (Berlinck, 1997) numa perspectiva histórica, destaque para o fim do século XIX e início do XX (1830/1930) e os terríveis desdobramentos tanto nos genocídios ocorridos durante a Segunda Guerra Mundial, como no mal-estar psíquico na atualidade. (Berlinck, 2000, 1997, pp. 5-14)

Com os olhos vivos no "individualismo possessivo" que se consolidou na modernidade e no que estamos denominando "individualismo fóbico" para a pós-modernidade, queremos rastrear as razões para uma tal insuficiência. O material empírico que temos interpretado referiu-se ao romance burguês vitoriano com destaque para os escritores Henrik Ibsen (1828-1906), August Strindberg (1849-1912), Anton Pavlovich Tchekhov (1860-1904) e Arthur Schnitzler (1862-1931). A pesquisa (Cerqueira Filho, 2008) apontou para outros desdobramentos na relação subjetividade e poder e na utilização do método clínico, com destaque para a filmografia de Ingmar Bergman e a obra de Paulo Emilio Salles Gomes (Cerqueira Filho, 2020). Desenvolvemos ainda os conceitos de pathos e ethos na obra de quatro importantes intérpretes do pensamento social brasileiro: Euclides da Cunha, Sergio Buarque de Holanda, Gilberto Freire e João Guimarães Rosa (Cerqueira Filho, 2013). Citamos um intelectual húngaro de nascimento, Paulo Rónai, mas que brasileiro se tornou pelo árduo trabalho com o idioma falado no Brasil (Martins, 2020).

Um exemplo de como o conceito se forja no paradigma estético-expressivo foi narrado e discutido num dos encontros científicos realizados pela Associação Universitária de Pesquisa em Psicopatologia Fundamental - AUPPF em Petrópolis (Hotel Casablanca) em torno da esquizofrenia e miscigenação que vai fazer emergir o nascimento dos construtos "miscigenação por mistura" e "miscigenação por justaposição" para a compreensão não só de um caso clínico, mas também e sobretudo nos estudos sobre formação histórica do Brasil (Berlinck, Koltai \& Canongia, 2001). Dizem os autores, citando no artigo precedente de Ludwig Binswanger quando narra o seguinte fragmento de caso clínico:

[...] Domingo, durante minhas visitas vespertinas, encontro o enfermo Hae mais de sessenta anos, esquizofrênico crônico (hebefrênico-paranoide), mas que ainda conserva suas faculdades intelectuais — serenamente sentado junto à sua mesa com um pedaço de língua fria (proveniente de seu jantar) estendida sobre sua careca. Surpreendido e divertido, pergunto-lhe o que, diabos, está fazendo. 
Com um tom muito sério, mostrando apenas um leve brilho "astuto" nos olhos, ele responde que o pedaço de língua refresca notavelmente sua cabeça ardente. ${ }^{3}$

[...] O que se perfila nesta cena é a questão da distância entre a língua morta que apazigua e ordena, fornecendo uma estrutura e um sentido ao pensamento, e a língua viva que borbulha produzindo uma ardência dentro da cabeça.

[...] A articulação sempre problemática da língua morta com a língua viva produziria não só um discurso expressivo, como ordenaria o borbulhar de palavras dando um sentido compartilhado ao pensado. A maioria dos humanos consegue conter o borbulhar impondo-lhe ordem e sentido. Depois, alguns, como os poetas, buscam incessantemente algo que borbulhe na língua morta. O insight, olhar para dentro, é o perceber de um borbulhar da língua que ocorre na ordenalidade morta da própria língua. Porém, essa distância na ausência de distância entre as duas línguas, como revela este caso, nem sempre se manifesta. A distância entre a língua morta, em sua concretude metonímica, e a língua viva, no seu borbulhar, não é ultrapassável nessa existência. Dependendo da disponibilidade das chamadas faculdades intelectuais, o sujeito pode se movimentar em busca de algo (uma língua morta) que lhe dê consistência expressiva. Porém, nem sempre isso é possível, revelando a existência de um espaço, de uma distância irredutível. Em outras situações (Berlinck, 2003), o sujeito acaba inventando uma língua própria, miscigenada, capaz de expressar sua errância e a sombra de uma língua morta inalcançável. Quando, na irredutibilidade da distância, o sujeito narrado por Binswanger busca uma integração entre língua morta e língua viva, depara-se com uma impossibilidade, uma cisão irredutível, onde a dialética não se realiza. Entretanto há, nesse sujeito, uma peculiaridade notável: ele "conserva as faculdades intelectuais", ou seja, há nele a possibilidade de integração entre a língua morta e a língua viva; ele consegue dar sentido e expressão tanto à língua morta, na figura da língua de boi sobre sua calva, como à língua viva, que denomina o borbulhar incessante de ideias. Além disso, consegue expressar esse paradoxo através de uma existência excêntrica, carregando uma língua de boi sobre sua calva. Eis, então, uma das manifestações da existência esquizofrênica. Ela revela não só a existência de duas línguas, a morta e a viva, que precisam estar integradas para garantir ao sujeito a busca de uma expressão que seja, ao mesmo tempo, própria da espécie e própria da singularidade, como revela a impossibilidade dessa integração, denunciando a distância irredutível entre

${ }^{3}$ Binswanger, L. Drei Formen missglückten Daseins. Verstiegenheit, Verschrobenheit, Manieriertheit (p. 71). Tübingen, 1956. [Três formas de la existencia frustrada. Exaltación, excentricidad, manerismo. Trad. Edgardo Albizu. Buenos Aires: Amorrortu, 1972]. (Cf. Berlinck, 2003). 


\section{EDITORIAL}

o morto e o vivo. A distância irredutível é, no caso narrado por Binswanger, assegurada pela estrutura óssea da cabeça e por uma pele sem pêlo, a calva. É como se a personalidade tivesse se desintegrado em complexos separados que não mais exercem influência mútua" como disse, uma vez, Jung para Freud (1993, p. 63). (Cf. Berlinck, 2003)

Trata-se, portanto, de um vigoroso esforço teórico para pensar novos conceitos, aqui de "insuficiência imunológica psíquica" e que conversa com os de "vulnerabilidade psíquica", "língua miscigenada", "miscigenação por mistura" e "miscigenação por justaposição" numa abordagem transdisciplinar. (Neder Cerqueira, 2015).

Um outro aspecto que podemos ressaltar é o denominado por Antônio Tabucchi de "furto das palavras" e logo quando elas são tão queridas. E não foi precisamente esse o caso que ocorreu durante o nazifascismo na Alemanha, Áustria, Hungria, Polônia, Itália, Espanha franquista, Portugal salazarista, França de Vichi e outros. Uma das questões a ressaltar, e na pós-modernidade, é que se dá algo similar com a chamada "nova direita" com o agravante de estarem neste rol os EUA de Donald Trump com os restos de sua governação... Há uma onda certamente agravada pela pandemia do coronavírus-COVID-19 em escala planetária, que convida a uma reflexão mais aprofundada.

Todavia, vamos nos fixar na Itália, a partir de Berlusconi, e no Brasil, a partir da eleição de Bolsonaro, para que, mesmo a voo de pássaro, não percamos o que mais impacta, aqui-e-agora, no sofrimento psíquico (pathos) das pessoas, e sem distinções ser precisamente o isolamento social que a quarentena apresenta na luta contra a pandemia da COVID-19. Ressalte-se o furto, que se deu precisamente com a palavra "solidariedade" do léxico das "esquerdas" que desde o "sindicato solidarnosc" viu-se emparedado pela direita e pelo conservadorismo mascarado. E essa foi uma das consignas mais usadas por Karl Marx: precisamente "solidariedade". Aqui, o engajamento do Papa João Paulo II em sua luta contra a teologia da libertação deu um tom de luta religiosa contra o comunismo, seja no leste europeu, seja na URSS, seja em escala internacional. Diga-se de passagem, que o momento da perestroika e glassnot acentuava o desconforto e desejo pelo fim do que se vivia nessas áreas. O compositor e músico brasileiro Gonzaguinha diria: "não dá mais pra segurar, explode coração". Em tradução livre é um entendimento bem realista para as palavras russas disseminadas pelo mundo por Mihail Gorbachev...

Vamos abordar agora duas conjunturas diversas, Itália e Polônia, pelo que servem, sem dúvida, ao Brasil de hoje e naquilo que permitem de esperança política possível. Na Itália, a juventude muito já ridicularizou o negacionismo, 
o terraplanismo, a negação da ciência etc. No "etc." colocamos como outro exemplo o tal furto das palavras. Na Itália há uma obra interessante, cuja primeira edição é de 2010. É um livro sério, mas divertido assinado pelo escritor Antonio Tabucchi (2010). E é ele quem nos conta sobre o senhor Palisse, general francês que no século XVI combateu e morreu em Pavía, Itália.

[...] sem ser um comilão, nem beberrão, pois seu nome ficou associado a uma austera vida militar, não merecia o elogio fúnebre que alguém deixou em voz elevada: "um quarto de hora antes de morrer, todavia, estava vivo..." Desde então uma obviedade deste tipo ficou denominada como "lapalissiano". Exemplo a água está molhada, "lapalissiano”...

Desde a chamada "nova era", referida a liderança de Berlusconi iniciou-se uma cruzada contra o pensamento lapalissiano, levando ao país a um lugar metafísico, onde a umidade da água já não é um dado evidente senão um mistério gozozo [...] Por aí acabaremos por chegar, por exemplo, ao ponto de sustentar que a falsificação dos balanços financeiros não é um delito porque não há uma lei que o defina como tal [...] (Tabucchi, 2010, pp. 17-20)

E por aí vai a obra curiosa de Tabucchi, que também é uma espécie de jogo que suscita uma verdadeira disputa entre fatos reais e fake news variadas onde, no aqui-e-agora da pandemia da COVID-19, oferece o campo de "batalha", a bem dizer ideológico, criticando-se por (mal)dita a ideologia... A conclusão é que a nova direita italiana acaba recepcionando bem tais boutades e, por exemplo, a autonomeação de alguns, que num passado nem tão remoto assim, eram fascistas declarados, no fim da guerra perdida e hoje mais que nunca ousam se declarar serem velhos partisans.

Mas é ainda sobre a Itália, que vamos chamar a atenção do leitor para a reviravolta nas expectativas de avanço da "direita" representada pela Liga Norte e em relação à postura e aos votos da "centro-esquerda" na eleição regional ocorrida na Emília-Romanha. As agências internacionais de notícias foram pródigas em informações já no dia 28 de janeiro de 2020. Um comício antifascista mostrava o chamado movimento dos "sardinhas"4 (votantes jovens e anônimos/eleitores desprezados), no caso, em Bolonha, de tradição esquerdista, pregando o voto contra a candidata da "Liga", Lucia Borgonzoni.

\footnotetext{
${ }^{4} \mathrm{O}$ movimento dos sardinhas foi liderado com destaque para o quarteto Andrea Gareffa, Giulia Trapolini, Mattia Sartori e Roberto Morotti, jovens intelectuais na faixa dos 30 anos e diplomados respectivamente em Comunicação \& Turismo, Fisioterapia \& Dança, Ciência Política, Engenharia com especialização em tratamento de lixo plástico.
} 


\section{EDITORIAL}

O adversário, Stefano Bonaccini garantiu o segundo mandato com 51\% dos votos contra $43 \%$ da adversária. Mas esse não é o ponto principal, pois a diferença nem foi tão grande. Para termos uma ideia do interesse que o movimento dos "sardinhas" despertou no eleitor, basta dizer que, não sendo o voto obrigatório, o comparecimento foi de $67 \%$ dos eleitores contra $36 \%$ no pleito anterior. Foi um belo trabalho de recuperação do voto daqueles tantos que estavam desacreditados da política. O tal "efeito sardinha", como referiu-se o jornal La Repubblica, trouxe alento à resiliência (Cerqueira Filho, 2019; Gonzaga, 2020) contra a direita e abalou o ímpeto da liderança maior de Matteo Salvini ${ }^{5}$ para pressionar por mudanças no governo central de Roma. É verdade que no sul da Itália (Calábria) a vitória da centro-direita foi ampla, com $55 \%$ dos votos contra $30 \%$ para a centro-esquerda... Mas o grito que ficou foi de esperança na consigna "dos sardinhas": solidarietá accoglienza rispetto diritti incluisione non-violenza antifascimo (solidariedade bem-vinda no respeito aos direitos, incluindo o antifascismo sem violência). Quase que a tradição de décadas do PCI e da esquerda italiana se viram em apuro, mas ao final das eleições regionais os votantes deram um efetiva lição nas urnas. É necessário estarmos atentos para esses movimentos populares de resgate da esperança contra a obediência e submissão irrestritas.

Esse revival do conservadorismo travestido em integrismo protofascista, o qual vem acompanhado pelo pensamento religioso das novas igrejas evangélicas - incluindo católicos fudamentalistas e especialmente nas questões de gênero, aborto, ambiental e de política sanitária, pois em muitas circunstâncias os fiéis estão sendo induzidos a não tomar a "vacina chinesa", como Donald Trump nomeou-a nos EUA e ecoou no Brasil pelo presidente Jair Bolsonaro. A demonimação "vacina chinesa" diz tudo, pois antecipa o medo e a fobia seja em relação aos chineses, seja à própria vacina. Em suma um bate-cabeça que não favorece a imunização da população. Nas universidades, estamos num território onde se acentua o pathos da melancolia, "resistência desistente", e do sentimento da vergonha, que frequentemente tem levado a situações marcadas pela depressão psíquica. Tal é o pathos contemporãneo que marca a conjuntura política no Brasil e outros países.

Carlo Ginzburg (2019), recentemente, chamou nossa atenção para o que designou como bond of shame (o laço da vergonha). Na leitura que faz

${ }^{5}$ Matteo Salvini, que foi vice-primeiro ministro e ministro do interior entre 2018 e 2019 , pertence a Lega Norde per l'independenza della Padania (extrema direita) fundado em 1991 no norte da Itália. 
de Aristóteles (1108), ${ }^{6}$ ele sugere que o filósofo grego listou a "vergonha" (aidós) entre as paixões (pathos), assinalando que ela (vergonha) não seria propriamente "uma virtude" (Ginzburg, 2019, p. 4).

Vamos direto ao ponto: teríamos, muitos de nós e nos dias de hoje, vergonha de sermos brasileiros? Seria, uma tal postura, próxima do popular "complexo de vira-lata", como Nelson Rodrigues o qualificou? De todo modo o que está presente no fundo de uma "cultura da vergonha", seja uma vergonha introjetada pela cultura da culpa (a partir de Santo Agostinho); seja associada à imposição de determinados valores mais restritos à comunidade social, quando o indivíduo se confronta com uma sanção externa que a comunidade a que pertence tomou para si (como no Japão); ou ainda na cultura islâmica, quando o laço da vergonha parece estar mais vinculado ao sentimento da vingança, Ginzburg "argumenta que o conceito de vergonha faz parte da relação entre o ser individual e o ser político" (Harazim, 2020, p. 2). "Fazer "coisas erradas" observado por "pessoas erradas" na "situação errada" (Williams, 1993, apud Ginzburg, 2019, pp. 219-223).

Nestas situações, não teríamos lá no fundo do sentimento de vergonha um complexo "afeto político autoritário" assentado no fundamentalismo, cuja 20 crítica, teoria, método e prática, caberiam também ao exercício profissional da Psicopatologia Fundamental?

E voltamos para a Polônia... O Papa polonês tem sido considerado sagrado como figura ímpar na hora em que lhe coube uma liderança sem par. O que não estava no script, entretanto, foi a perseverança do machismo fundamentalista que destoa numa Europa que sustenta a laicização e a reivindicação dos direitos das mulheres... Não se esperava um questionamento tão contundente vindo da Polônia radicional, nacionalista e católica, há anos moldada nesta matriz, fosse partir justamente das mulheres. O partido ultraconservador Lei e Justiça, tendo na presidência Andrzej Duda, assistiu boquiaberto um tal questionamento e partindo de quem menos o poder constituído esperava...

Muitos creem que a pandemia da COVID-19 aqui também teve sua participação nos distintos momentos da pandemia, $1^{\mathrm{a}}$ e $2^{\mathrm{a}}$ ondas onde acentuou-se o individualismo e o relaxamento na quarentena. A máscara parece ter caído no país do Solidarnosc (Solidariedade), palavra esta furtada enquanto bandeira da esquerda e desde os tempos da Revolução Francesa (1789 - Liberté, Igualité, Fraternité). Foi Karl Marx que observara que tais

\footnotetext{
${ }^{6}$ Aristóteles (1108). Ética nicomachaeana (pp. 30-31), apud Ginzbug (2019).
} 


\section{EDITORIAL}

expressões falavam ao conceito abstrato de cidadão (citoyen), mas não aos homens e mulheres reais, viventes de carne e osso. Pela primeira vez muitos poloneses questionaram abertamente o papel da Igreja a ponto de invadir uma missa de domingo para protestar contra a influência política do clero. Outros setores também se mobilizaram pela gestão das políticas de saúde na segunda onda da pandemia.

Não será que o isolamento social e a quarentena que estão a exigir um mínimo de solidariedade fraterna e já agora, quando a solidariedade internacional que - por certo derrotou o nazismo — revelou este último como postura individualista radical? As mulheres não se dispõem a obedecer a sentença do Tribunal Constitucional que em 22 de outubro restringiu ao máximo as possibilidades de abortar em um país que já estava entre os mais restritivos de toda a Europa na interrupção voluntária da gravidez. Estado de Direito perdido para a nova direita, os ataques constantes aos movimentos coletivos LGBTQ+, incluindo o deboche sobre as políticas de saúde em plena pandemia revelaram que "o Rei está nu"... As pessoas odeiam cada vez mais Kaczynski [vice-primeiro-ministro e líder do partido do Governo]. A idolatria a Karol Wojtyla não impediu às mulheres tomarem conhecimento dos casos de pedofilia dentro da Igreja Católica e com ausência de investigação séria e responsável. Isto aparece aos observadores como o que mobilizou a juventude e em particular as mulheres. As ruas de Varsóvia têm sido tomadas pelas mulheres (falou-se em 100 mil delas numa das últimas ocasiões). Enquanto isso o presidente Andrzej Duda anunciou que apresentará um projeto de emenda à lei do aborto para voltar a legalizar a interrupção da gravidez por problemas de formação do feto, mas somente nos casos em que a morte do bebê for inevitável. Entretanto, não é só. As agências internacionais de notícias vem apontando forte internacionalização ${ }^{7}$ e tem feito referência a organizações católicas fundamentalistas bem constituídas financeiramente com aplicações de vultosos recursos entre elas.

${ }^{7}$ Entre outras ver a reportagem

https://noticias.uol.com.br/internacional/ultimas-noticias/2020/12/28/os-milhoes-enviados-da-polonia-para-radicais-da-tfp-no-brasil-e-pelo-mundo.htm

Tais notícias impressionam vivamente e mostram como a nova direita está articulada em vários países europeus e além fronteiras. 


\section{Referências}

Barreto Coutinho, D. M., \& Lima Fonteles, C. S. (2019). A perspectiva transdisciplinar da psicanálise. Teoria e Pesquisa, 35, e 35440.

Berlinck, M. T. (1997, nov.). Insuficiência Imunológica Psíquica. Boletim de novidades da Livraria Pulsional, 10(103), 5-14.

Berlinck, M. T. (2000). Psicopatologia fundamental. São Paulo, SP: Escuta.

Berlinck, M. T. (2003). Espaço e existência. Apresentado no VII Encontro Científico da Associação Universitária de Pesquisa em Psicopatologia Fundamental - AUPPF, Hotel Casablanca, Petrópolis, RJ, de 4 a 7 de setembro de 2003.

Binswanger, L. (1972). Drei Formen missglückten Daseins. Verstiegenheit, Verschrobenheit, Manieriertheit (p. 71). Tübingen. [Três formas de la existencia frustrada. Exaltación, excentricidad, manerismo. Trad. Edgardo Albizu. Buenos Aires, AR: Amorrortu]. (Trabalho original publicado em 1956).

Cerqueira Filho, G. (2002). Édipo e excesso. Reflexões sobre Lei e Política. Porto Alegre, RS: Sérgio Antônio Fabris Editor.

Cerqueira Filho, G. (2005). Autoritarismo afetivo: a Prússia como sentimento. São Paulo, SP: Escuta.

22 Cerqueira Filho, G. (2008). Estridente Strindberg /Strindbergs Echos. Edição bilíngue português/alemão. Rio de Janeiro, RJ: NPL.

Cerqueira Filho, G. (2013). Sufoco nas alturas: sobre Páramo, de Guimarães Rosa. Passagens. Revista Internacional de História Política e Cultura Jurídica, também disponível em: https://www.usp.br/bibliografia/obra.php?cod=22430\&s=grosa Para a versão em inglês (Cerqueira Filho, 2013): http://dx.doi.org/10.5533/19842503-20135201eng Tradução Lindsay Spratt, revisão por Hernani Cavalheiro Neto e David Yann Chaigne.

Cerqueira Filho, G. (2019). Cultura e... resiliência. Rio de Janeiro, RJ: Lúmen Juris.

Cerqueira Filho, G. ((2020). Textos Pré-póstumos: Paulo Emílio Salles Gomes revisitado. In G. Neder, A. P. B. R. da Silva, \& J. R. M. Gomes (Orgs.). Direito, Estudos Culturais e Sociabilidades Políticas (pp. 18-36). Rio de Janeiro, RJ: Autografia.

Cerqueira Filho, G., \& Neder, G. (2020). Projeto JFK: Juntar Sigmund Freud \& Hans Kelsen - uma aproximação entre subjetividade e direito. Rio de Janeiro, RJ: Mauad X.

Dumont, L. (1966). Homo Hierarquicus. Essai sur le système de caste. Paris, FR: Gallimard,

Dumont, L. (1992). Ensaios sobre o Individualismo. Lisboa, PT: Dom Quixote. (Trabalho original publicado em 1986). Recuperado de <https://www.wook.pt/ livro/ensaios-sobre-o-individualismo-louis-dumont/70846>. 


\section{EDITORIAL}

Dumont, L. (2000). Homo Aequalis. Gênese e plenitude da ideologia econômica. São Paulo, SP, EdUSC. (Trabalho original publicado em 1976).

Fédida, P. (1991). Psiquiatria e existência: textos reunidos por Pierre Fédida, Jacques Schotte. Grenoble, FR: Editions Jerôme Millon, Collection Krisis.

Freud, S. (1914). Neuroses de transferência: uma sintese (Abram Eksterman, trad.). Rio de Janeiro, RJ: Imago, 1987.

Garmendia, G., \& Schnaith, N. (1973). Thomas Hobbes y la Orígenes del estado burguês. Buenos Aires, AR: Siglo XXI.

Ginzburg, C. (2019, nov.dec.). The bond of chame. New Left Review-NLR-, 120.

Gonzaga, D. (2020, jan.abr.). Resiliência como posição política. Passagens.

Revista Internacional de História Política e Cultura Jurídica (on line), 12(1), 164-171.

Harazim, D. (2020). Depois do carnaval. O Globo, Rio de Janeiro, 28.2.2020, p. 2.

Houlsman, L. (1993). Penas perdidas. O sistema penal em questão. Niteroi, RJ: Luam Editora.

Innerarity, D. (2011). The democracy of Knowledge. New York, NY: Bloomsbury Publishing.

Kelsen, H. (1922). Begriff des Staates und Sozialpsychologie Mit besonderer Berundsichitgung von Freuds theorie de Masse. IMAGO VIII (Band 1922).

Legendre, P. (1983). O amor do censor. Ensaio sobre a ordem dogmática. Rio de Janeiro, RJ: Forense Universitária3.

Martins, A. C. I. (2020). O homem que aprendeu o Brasil - A vida de Paulo Rónai. São Paulo, SP: Todavia.

Mcpherson, C.B. (1979). Teoria Política do individualismo possessivo de Hobbes até Locke. Rio de Janeiro, RJ: Paz e Terra.

Neder, G. (2007). Iluminismo jurídico-penal luso-brasileiro: obediência e submissão.

( $2^{\mathrm{a}}$ ed.). Rio de Janeiro, RJ: Revan. Prefácio de Cerqueira Filho, Gisálio.

Neder Cerqueira, M. (2015). O homem desconfortável: poder e modernidade em Arthur Schitzler. Rio de Janeiro/Curitiba: Prismas.

Sachs, H. (2017). Freud maestro e amico. Roma, IT: Editora Castelvecchi.

Santiago, S. (2020). Fisiologia da composição. Recif, PE: Sepe.

Tabucchi, A. (2010. La Oca del passo: notícias desde la obscuridade que estamos atravessando. Barcelona, ES: Editorial Anagrama. ColeciónArgumentos.

Williams, B. (2020). Shame and necessity, Berkeley, UCLA Press, 1993, pp.78 e 79; 219-223. Apud Ginzburg, C. Sobre a vergonha, Revista Serrote, Instituto Moreira Sales-IMS0.

Zaffaroni, E. R. (1991). Em busca das penas perdidas. Rio de Janeiro, RJ: Revan. 
Zaffaroni, E. R. (2004). Culpabilidade por vulnerabilidade, Revista Discursos Sediciosos, Crime, Direito e Sociedade, 14, 31-48.

Cosme Velho, 02 de fevereiro de 2021.

Citação/Citation: Cerqueira Filho, G. (2021, março). Editorial. Possessividade e Fobia: uma reflexão para agora. Revista Latinoamericana de Psicopatologia Fundamental, 24(1), 11-24. http://dx.doi.org/10.1590/1415-4714.2021v24n1p11.1.

Editoras/Editors: Profa. Dra. Ana Maria Galdini R. Oda e Profa. Dra. Sonia Leite

Recebido/Received: 29.1.2021 / 1.29.2021 Aceito/Accepted: 31.1.2021 / 1.31.2021

Copyright: (C) 2009 Associação Universitária de Pesquisa em Psicopatologia Fundamental/ University Association for Research in Fundamental Psychopathology. Este é um artigo de livre acesso, que permite uso irrestrito, distribuição e reprodução em qualquer meio, desde que o autor e a fonte sejam citados / This is an open-access article, which permits unrestricted use, distribution, and reproduction in any medium, provided the original authors and sources are credited.

\section{GisÁlio Cerqueira Filho}

Sociólogo e cientista político. Professor Titular de Sociologia da Universidade Cândido Mendes - UCAM (Rio de Janeiro, RJ, Br); Professor Titular de Teoria Política da Universiade Federal Fluminense - UFF (Niteroi, RJ, Br). Atuou e atua em variados programas de pós-graduação (PUC-RIO, ENSP-FIOCRUZ, UFRJ, UFF). Hoje é supervisor do "Seminário Internacional Permanente sobre Subjetividade e Política" [GESP-LCP-GHT-UFF) http://www.historia.uff.br/lcp. É pesquisador sênior, Doutor em Ciência Política (USP-1980), pós-doutorado com Gizlene Neder e estágio na Biblioteca Nacional de Lisboa, Portugal (1999). Pesquisador titular na Associação Universitária de Pesquisa em Psicopatologia Fundamental - AUPPF (São Paulo, SP, Br). Editor de Passagens - Revista Internacional de História Politica e Cultura Jurídica on line http:// www.historia.uff.br/revistapassagens/ É membro do Research Committee on Sociology of Law (RCSL/ ISA). Como autor Gisálio Cerqueira Filho publicou A questão social no Brasil: crítica do discurso político (Rio de Janeiro: Civilização, 1982). Como organizador, (Gisálio Cerqueira Filho), Carlos Alberto Barreto, Eduardo Mascarenhas, Fábio Lacombe, Hélio Pellegrino, Joel Birman, Wilson Chebabi. Crise na psicanálise (Rio de Janeiro: Graal, 1982), além de vários outros livros e ensaios.

Rua Cosme Velho, 67/501

22241-125 Rio de Janeiro, RJ, Br

gisalio.cerqueira@gmail.com

https://orcid.org/0000-0001-5047-4376

This is an open-access article, which permits unrestricted use, distribution, and reproduction in any medium for non-commercial purposes provided the original authors and sources are credited. 